\title{
IBN JALDÚN: PRECURSOR DE LA SOCIOLOGÍA
} HISTÓRICA

\author{
IBN KHALDUN, THE FORERUNNER OF HISTORICAL \\ SOCIOLOGY
}

\author{
Luz Araceli González Uresti ${ }^{1}$ \\ ORCID: https://orcid.org/0000-0003-3627-644X \\ Zidane Zeraoui ${ }^{2}$ \\ ORCID: https://orcid.org/0000-0001-8121-8455
}

\section{RESUMEN}

"Ibn Jaldún, precursor de la sociología histórica" rescata al filósofo de la Edad Media islámica, no solamente como historiador, sociólogo, o pensador realista, sino como precursor de la sociología histórica además de ser el fundador de la sociología, "ilm al-iytimaa", la "ciencia de la sociedad” como él la denominó. Este artículo busca unir estas dimensiones de Ibn Jaldún presentes en su obra magna, la muqadima, y destaca que su trabajo sobre relaciones internacionales fue un estudio fundamentado en el marco teóricometodológico que seis siglos más tarde teorizara Raymond Aron en su trabajo Paz y guerra entre las naciones.

Palabras claves: Sociología histórica, realismo, ciencia de la historia, relaciones internacionales, pensamiento Islámico, sociología.

\begin{abstract}
"Ibn Khaldun, the forerunner of historical sociology", rescues the philosopher of the Islamic Middle Ages, not only as a historian, sociologist, or realist thinker, but as a forerunner of historical sociology as well as being the founder of sociology, "ilm al-iytimaa", the "science of society" as he called it. This article seeks to unite these dimensions of Ibn Khaldun present in his magna work, the muqadima, and emphasizes that his work on international relations was a study based on the theoretical-methodological framework that six centuries later theorized Raymond Aron in his work Peace and war among nations.
\end{abstract}

Keywords: Historical sociology, Realism, Science of History, International Relations, Islamic Thought, Sociology.

1 Doctora en Relaciones Internacionales y profesora-investigadora del Tecnológico de Monterrey, Campus Monterrey. laguresti@itesm.mx

2 Doctor en Ciencia Política y profesor-investigador del Tecnológico de Monterrey, Campus Monterrey. zeraoui@itesm.mx 


\section{Introducción}

En un mundo postmoderno y postindustrial en el que parecen anteponerse los esquemas utilitaristas y pragmáticos, en el que la tecné se yergue sobre la gnosis, y donde la tradición del pensamiento clásico parece perder terreno, el estudio de las corrientes político-sociales necesariamente debe considerar la larga tradición del filosófico que a lo largo de varios siglos ha nutrido al mundo contemporáneo. Escuelas de oriente, occidente y diversas regiones del mundo, confluyen e integran hoy, en la teoría social, fundamentos indispensables para la comprensión de los fenómenos actuales. En esta línea, incluimos al sociólogo Ibn Jaldún dentro de la tradición teórica de las Relaciones Internacionales, en particular por su aporte en el pensamiento de lo que en el siglo XX se denominaría por Raymond Aron, la Sociología Histórica por sus análisis de la realidad internacional de su tiempo desde una perspectiva de la "Ciencia de la Sociedad", como el mismo la denomina y del análisis histórico.

Sin duda alguna, Ibn Jaldún requiere ser revisitado dado el alcance y la trascendencia de sus aportes (Zeraoui, 2013). Su caso es paradigmático. “(...) fue el más grande filósofo e historiador que dio nunca el islam y uno de los más grandes de todos los tiempos" (Lacoste, 1971, p. 58). Este pensador del siglo XIV ha sido referido como el fundador de la historia social (Guarch, 2008), de la historia del Tercer Mundo (Lacoste, 1984), asimismo se le ha reconocido como padre de la sociología ${ }^{3}$ (Alatas, 2014), como teórico de la política (Rabi, 1967), e inclusive como pionero de la economía (Nashat, 1945) y ahora nos referiremos a él como precursor de lo que en el siglo XX Raymond Aron postuló como Sociología Histórica.

En su obra monumental, Al-Muqaddimah (Introducción a la historia universal) ${ }^{4}$ (Ibn Jaldún, 1979), el pensador magrebí logró integrar al estudio de los imperios de su tiempo, las relaciones de poder entre ellos, así como la dimensión analítica sociológica de la historia, al proponer un estudio en el cual, en las particularidades históricas, se reconoce la incidencia sociológica al postular, ya en su tiempo, la trascendencia de las llamadas fuerzas profundas, concepto que el

3 La Revista Mexicana de Sociología, 7-22, publicó hace más de 50 años un trabajo en torno a la vertiente sociológica de Ibn Jaldún por Chaix-Ruy, Jules (1954).

4 Versión árabe de 1295 páginas. Existe una traducción al castellano de Juan Feres con un estudio preliminar, revisión y apéndices de Elías Trabulse, no siempre acertada, publicada en México en 1977, por el Fondo de Cultura Económica bajo el título de Introducción a la Historia Universal. La obra magna de Ibn Jaldún no fue traducida en su totalidad en el mundo occidental. De hecho, cuando se 'descubre' al pensador magrebino (la primera traducción en Europa se hizo en francés en 1863) por Slane y solamente se tradujo su análisis de las dinastías del Magreb y no la totalidad de su trabajo, a pesar del reconocimiento temprano de su genio en el Occidente. 
mundo contemporáneo ha reconocido en autores como Renouvin y Durosselle (1968), ambos presentes en el pensamiento de Aron.

El mundo islámico que fue uno de los principales centros del pensamiento universal desde el siglo VII, entra en decadencia a partir del siglo XIII. Es en este contexto de su atraso que Ibn Jaldún, considerado como padre de la sociología y la ciencia histórica, irrumpe con su obra cumbre que marca el último sobresalto de la grandeza del pensamiento de su época. Su obra se enfoca a la reflexión histórica de las relaciones internacionales de su época, pero es el fundador de nuevas ciencias como la sociología y la antropología cultural de la civilización arabo-musulmana.

Así que "Ibn Jaldún concibió y formuló una filosofía de la historia que es, sin duda, el trabajo más grande que jamás haya sido creado por una inteligencia, en ningún tiempo y ningún lugar" (Toynbee, 1935, p. 332).

Para comprobar la hipótesis que nos ocupa, iniciaremos con la presentación de las principales ideas de Raymond Aron sobre la sociología histórica, consagradas en su obra Paz y guerra entre las naciones (Aron, 1985). En el segundo apartado, presentamos el marco histórico, político y social en el que Ibn Jaldún forja su pensamiento. En el siguiente apartado, se analizan las dimensiones políticas, sociológicas e históricas del pensador magrebino, al demostrar con este recorrido que Ibn Jaldún, además de ser el precursor de la ciencia de la sociedad, es también pionero de la sociología histórica, ampliamente trabajada en el siglo XX en el contexto de las escuelas sociológicas europeas.

\section{Raymond Aron y la sociología histórica}

Raymond Aron, filósofo y sociólogo francés reconocido como un lúcido analista de la realidad social y la política de su tiempo, forjó una línea de pensamiento profundamente influida por la filosofía de la historia y por la sociología alemana, dimensiones mutuamente complementarias, presentes en su prolífica producción intelectual.

En el campo específico de la teorización en relaciones internacionales, la escuela francesa, representada en gran medida por Raymond Aron, fue la respuesta europea a las proposiciones norteamericanas y anglosajonas para el análisis de la dinámica mundial. La sociología histórica parte de una premisa fundamental, al sostener que el estudio de la sociedad internacional se debe realizar desde la consideración del análisis de la naturaleza de la misma sociedad, lo cual implica que se tengan fundamentos teóricos de la sociología y empíricos de la historia 
(Gutiérrez Pantoja, 1997), aunque se le reconoce también, como parte de la línea de realismo.

La propuesta de Aron denominada Sociología Histórica fue acuñada por él mismo. Sus ideas se pueden sintetizar en la siguiente cita: "pasando de la teoría formal a la determinación de las causas, y luego al análisis de una coyuntura singular, espero ilustrar un método, aplicable a otros temas, y mostrar a un mismo tiempo los límites de nuestro saber y las condiciones de las elecciones históricas" (Aron, 1985, p. 22). Este método se sitúa sobre los postulados tanto de la sociología como de la historia, al tomar en cuenta las dimensiones sincrónicas y diacrónicas de la realidad que se va a estudiar. Como él mismo estableció:

Todo estudio concreto de las relaciones internacionales es, pues, un estudio sociológico e histórico ya que el cálculo de las fuerzas reenvía el número, al espacio, a los recursos, a los regímenes (militar, económico, político y social) y estos alimentos a su vez constituyen los envites de los conflictos entre los Estados (Arenal, 1987, p. 152).

La propuesta teórico-metodológica de Aron se basa en una reflexión racional de las relaciones internacionales que integra un análisis sociológico, histórico así como normativo con los cuales pretende establecer el marco en el que se sitúa la esencia específica de la relaciones internacionales. Aron afirma que "los dos conceptos de la teoría no son contradictorios sino complementarios: la esquemática racional y las proposiciones sociológicas constituyen momentos sucesivos en la elaboración conceptual de un universo social" (Arenal, 1987, p. 146).

Esta propuesta metodológica implicó cuatro dimensiones de análisis: teórico, sociológico, histórico y praxeológico. Estas son las piedras angulares sobre las que Aron levanta su concepción para el análisis de las relaciones internacionales y articula lo que hasta nuestros días conocemos como Sociología Histórica.

El significado que otorga Aron a la teoría en su propuesta no equivale exactamente a la entendida en sentido general; le otorga visión en términos de definición de los conceptos necesarios para el análisis y la conceptualización de la realidad observada. Es decir, este enfoque consiste en precisar la naturaleza del "juego" analizado, así como las reglas a las que está sometido.

En esta línea la dimensión teórica ofrece al estudioso tres aportes sustantivos: 1) indica al sociólogo y al historiador los principales elementos que debe llevar consigo una descripción de la coyuntura o del sistema a analizar, así como los objetivos y los actores partícipes. 2) si el sociólogo o el historiador, al ir más allá de la pura descripción, quieren comprender la actuación de los actores in- 
ternacionales, pueden utilizar la conceptualización como criterio de racionalidad y confrontar la conducta que según este mismo enfoque hubiera sido lógico, y 3) el sociólogo o el historiador pueden y deben interrogarse sobre las causas que determinan la formación, la transformación o la desaparición de los sistemas internacionales. De esta manera, "la teoría nos sugiere una enumeración de los fenómenos-efectos, de los determinados, a los que el sociólogo se ve invitado a buscar los fenómenos-causas, los determinantes" (Aron en Arenal, 1987, p. 149).

La segunda dimensión de la propuesta de Aron (1985) en su Paz y guerra entre las naciones es la sociológica. En este punto el autor se interroga acerca de si es posible una explicación de la conducta de los actores, una explicación global de las alternativas entre paz y guerra. Se trata del estudio de los determinantes, de las variables materiales, morales, geográficas, demográficas, económicas, políticas y psicológicas que condicionan la política exterior e influyen en los acontecimientos internacionales y de las regularidades que se producen en la esfera internacional. Ello permite establecer las regularidades de la conducta, distinguir los diferentes tipos de conflicto y eventualmente formular hipótesis sobre la evolución de determinadas situaciones Aron, 1985).

No obstante, para Aron, esta dimensión sociológica necesita de la historia, pues se requiere observar el curso de los acontecimientos, la evolución de los métodos, la diversidad de las técnicas y de los temperamentos. El sociólogo debe evitar razonar en abstracto. De ahí que el estudio de los conceptos y los determinantes no es satisfactorio si no se puede aplicar a usos o situaciones concretas. De esta manera se hace necesario recurrir a la historia. Esta tercera dimensión en su propuesta, la consagra a la coyuntura actual, en la que describe la constelación de procesos en un momento dado, los cuales intenta poner a prueba en primer lugar a través de un análisis que se deduce de la teoría y de la sociología. Es en la historia, según Aron en donde se pueden identificar las regularidades sociológicas cada vez que aquella parte de condiciones únicas, singulares y coyunturales.

El cuarto y último elemento de la propuesta de la sociología histórica de Aron es la dimensión praxeológica que es la parte normativa y filosófica en la que se ponen en duda de nuevo las hipótesis iniciales. En el análisis de relaciones internacionales nos dice Aron que, no basta con mirar, escribir, señalar regularidades es necesario juzgar, actuar, fijar las reglas morales de la acción. En definitiva, hacer operacional la teoría, darle una finalidad no solo cognoscitiva, sino también pragmática. 
"Las relaciones diacrónicas y sincrónicas que se dan entre las cuatro dimensiones de la propuesta llevan a Aron a señalar que el historiador es tanto deudor del teórico como del sociólogo. El teórico le facilita los instrumentos de comprensión (conceptos, funciones y modelos) y el sociólogo le indica el marco en que se desenvuelven los sucesos y que ayuda a captar la diferencia entre los distintos tipos sociales. En tanto que la función de la sociología es buscar las circunstancias que influyen sobre las consecuencias de los conflictos entre los Estados, sobre los objetivos que se asignan sus autores y sobre la fortuna de las naciones y de los imperios... La sociología muestra cómo varían las determinantes (espacio, número, recursos) y los sujetos (naciones, regímenes, civilizaciones) de las relaciones internacionales" (Gutiérrez Pantoja, 1997, p. 253).

Para Aron, el historiador relata los acontecimientos de la política exterior y sigue el devenir de una unidad política, de un sistema diplomático o de una civilización considerada como un conjunto singular. El sociólogo busca, por su parte, proposiciones de una cierta generalidad, relativas al poder, los objetivos de las unidades políticas, la naturaleza en los sistemas, los tipos de paz y guerra, sin que los actores hayan tenido necesariamente conciencia de ello. La teoría nos sugiere una enumeración de los fenómenos-efecto, los determinados, a los que el sociólogo se ve invitado a buscar fenómenos-causa, los determinantes. El sociólogo está en situación de negar hechos o relaciones de alguna generalidad si consigue dividir la materia en función de los últimos y no de los fenómenosefectos. La enumeración de éstos debe ser sistemática si es que se espera que el ensayo sociológico tenga alguna utilidad (Aron, 1985).

Según el teórico francés la función del sociólogo queda delimitada por su búsqueda de las causas de los acontecimientos sociales internacionales. Además, al proponer sus postulados cognoscitivos sugiere una nueva perspectiva para el entendimiento de la fenomenología internacional que se identifica como la sociología histórica. Aron concluye que solo el sociólogo que utilice el método histórico puede llegar a ser el Consejero del Príncipe.

Si bien estas ideas se han identificado como propuestas originales del pensamiento del siglo XX, es evidente al revisar la vida y la obra de Ibn Jaldún que estas ya estaban presentes y conceptualizadas por el autor magrebino más de seis siglos atrás.

Después de haber presentado los planteamientos de Raymond Aron sobre su Sociología Histórica, es necesario revisar el pensamiento de Ibn Jaldún, para encontrar las semillas de la teoría de Aron, que constituye la idea central de este ensayo. 


\title{
2. Ibn Jaldún: de la teoría a la praxeología
}

\begin{abstract}
Abd Ar-Rahman Ibn Jaldún El Hadramiyu ${ }^{5}$ nació en 1332 en Túnez ${ }^{6}$ de una familia burguesa árabe de origen andaluz, procedente de Sevilla, que tuvo importantes cargos en la administración islámica: altos funcionarios o políticos. Sin embargo, el mismo nombre o nisba ${ }^{7}$ en árabe que lleva Ibn Jaldún (El Hadramiyu) nos indica que su familia tiene su origen más antiguo en el Hadramaut (Yemen actual) y se instalaron en Sevilla alrededor del siglo VIII. Sus antepasados trabajaron para los imperios almorávide y almohade hasta 1228 , año que emigraron a Ceuta. Uno de sus antepasados fue el geómetra, astrónomo y médico sevillano Abu Muslim Ibn Jaldún (m.1057). Mucho antes del nacimiento de Ibn Jaldún, el historiador cordobés Ibn Hayyán (987-1076) dijo que "la familia Jaldún es hasta el presente una de las más ilustres de Sevilla. Ha brillado siempre por el elevado rango que ocupan sus miembros en los mandos militares y en las ciencias" (Elía, s/f: 9).
\end{abstract}

Ibn Jaldún estudió en la corte Merinida ${ }^{8}$ en donde tuvo acceso a la cultura filosófica y a la especulación racionalista. Fue educado en los principales centros del pensamiento de la época, Túnez, pero sobre todo Fez, capital del Imperio marroquí. Estudió el Corán, la Sunna (tradición de Mahoma), las distintas ramas del derecho islámico (la Sharia), en particular la malikí que predomina en el Magreb, y la teología dialéctica. Estudió también literatura, filosofía, matemáticas y astronomía.

Durante su juventud, se benefició ampliamente con la frecuentación de las brillantes inteligencias que rodean la dinastía marroquí. Uno de ellos, Abelli, se convierte en su maestro preferido y parece ser que desempeñó un papel primordial en la formación intelectual del futuro historiador. Fue uno de los más célebres filósofos de la época y es el comentarista y el continuador de los grandes filósofos racionalistas, Averroes, Avicena, Farabi, Razes. Aunque, como en aquella época, siglo XIV, el Magreb pasa por un período de reacción devota, las

5 Cfr. Ibn Jaldún (1979), es una obra monumental de 1295 páginas. Existe una traducción al castellano de Juan Feres con un estudio preliminar, revisión y apéndices de Elías Trabulse, no siempre acertada, publicada en México en 1977, por el Fondo de Cultura Económica bajo el título de Introducción a la Historia Universal. La obra magna de Ibn Jaldún no fue traducida en su totalidad en el mundo occidental. De hecho, cuando se 'descubre' al pensador magrebino (la primera traducción en Europa se hizo en francés en 1863 por Slane), solamente se tradujo su análisis de las dinastías del Magreb y no la totalidad de su trabajo, a pesar del reconocimiento temprano de su genio en el Occidente. Para mayor profundidad Cfr. Martínez-Gros, 2006.

6 El lugar de nacimiento de Ibn Jaldún es incierto: para los argelinos, el gran pensador nació en Argelia, pero creció en Túnez.

7 En la tradición árabe no existen apellidos en el sentido occidental. Sin embargo, muchas familias se conocen por su nisba o su origen étnico o geográfico.

8 Merinides: dinastía árabe que en el siglo XIV dominó el Magreb. 
obras de estos filósofos son juzgadas sospechosas y no son estudiadas. Gracias a Abelli, Ibn Jaldún se beneficia, durante tres años, de una enseñanza filosófica y de una formación racionalista excepcional para aquella época, ya obscurantista. Su maestro, que se alberga en la misma casa de los Jaldún, le inculca una formación lógica, extremadamente fuerte, que le permite asimilar el pensamiento de los grandes filósofos. Parece que Ibn Jaldún, sintió una enorme atracción por sus doctrinas. La influencia que Abelli ejerce sobre Ibn Jaldún es tal, que el alumno se decide a abandonar Túnez para reunirse con su maestro que había regresado a Fez (Lacoste, 1971).

En esta época, le toca a Ibn Jaldún ser testigo de una serie de convulsiones políticas. Al término de esta intricada confusión política, Ibn Jaldún se encuentra todavía bien situado en el partido vencedor: en menos de 4 años, sin tener en cuenta a los pretendientes notables, cinco sultanes han sido puestos en el trono y desposeídos poco después. Cuatro fueron asesinados. No se puede contar, entre los parientes y aliados de cada uno de estos soberanos efímeros, el número de aquellos que fueron asesinados bien sea después de la victoria de aquel a quien habían ayudado a vencer y que quería eliminar posibles rivales, bien después de su caída a manos de los partidarios de su sucesor. Ibn Jaldún consigue desempeñar un papel político considerable bajo cada uno de estos sultanes, pues sabe hacer gala de un verdadero genio de la intriga en el seno de esta tela de araña que cambia continuamente: un sultán apenas acaba de ser investido, y ya aquellos que le han hecho subir al trono entran a formar parte de la conspiración que le derribará (Lacoste, 1971, p. 12).

Yves Lacoste diría de Ibn Jaldún que "aunque presentían su importancia, los historiadores del siglo XIX y de comienzos del XX, apasionados por la historia cronológica, no comprendían bien (su obra). La importancia primordial que éste concedió a las estructuras sociales les pareció que caracterizaba, no una concepción eminentemente científica y particularmente rica de la historia, sino la actitud de un filósofo" (Lacoste, 1971, p. 14). Es justo en esta dimensión en que podemos encontrar un interesante y sólido paralelismo con Raymond Aron, cuando este último hace referencia a las llamadas fuerzas profundas en el análisis histórico. Es precisamente, el fondo del pensamiento jalduniano buscar las fuerzas de la historia y no limitarse a la fenomenología aparente de los acontecimientos.

Al hacer un resumen de una obra metodológico-filosófica de Al Razi , Ibn Jaldún entiende la necesidad del islam para un nuevo esfuerzo de pensamiento

9 Al Razi o Razhes es más conocido por su obra en la medicina como Ijlas Nafsani (tratado psicoterapéutico), sus investigaciones sobre sarampión y viruela y sobre todo por su enciclopedia El Hawi en 25 volúmenes que fue utilizada (con el Canón de la medicina de Avicena) hasta el siglo XVII en la 
y de reflexión sociológica, pero al mismo tiempo tiene conciencia de los límites sociohistóricos sobre tal pensamiento por la decadencia del Imperio de la época. Así, su obra se enfoca en adecuar los sistemas de pensamiento a las estructuras reales de su momento, como Aron postuló que todo estudio de las relaciones sociales, debe realizarse desde la consideración y el análisis de la naturaleza de esta misma sociedad.

Su vida filosófica y científica alterna con un trabajo diplomático y políticoadministrativo en las altas esferas del poder islámico tanto en Túnez, en un periodo en donde la peste hace estragos en el país (y en su familia). Entre 1350 y 1372 colabora con varias dinastías en el Magreb y en Al Andalus (la península ibérica para el mundo islámico), al participar de las intrigas del poder y de las mediaciones (fue enviado en una misión secreta a Sevilla con Pedro el Cruel). Así, Ibn Jaldún tiene una intensa actividad política antes de la caída en desgracia de su familia y de él mismo. De hecho, es encarcelado dos veces durante su actividad político-administrativa. Durante este periodo trabaja para los gobernantes de Túnez y de Fez (Marruecos), de Granada (Al-Andalus) y de Bedyaia $^{10}$ y de Biskra (ambos al este de Argelia). En 1375, Ibn Jaldún, frente a la turbulencia política de África del Norte, se retira a Granada, pero por su pasado político es expulsado del país.

Estas experiencias le permiten entender los mecanismos políticos que gobiernan el ejercicio del poder y la naturaleza del poder político, que serán utilizados cuando trate de analizar la historia universal de su tiempo. Nuevamente, la referencia a Aron resulta imprescindible, ya que para este filósofo la dimensión praxeológica en el análisis es indispensable, es decir el estudioso no debe ser solo filósofo, sino debe llevar al terreno de la acción su conocimiento, la teoría sin práctica pierde significado. Ibn Jaldún evidencia estos aspectos al ser, como filósofo de la historia, y hombre de acción en las esferas políticas de su época.

Al participar en todos los reinos de África del Norte, tanto en Fez como en Tlemcen, Túnez, Bedjaia, Biskra y hasta Granada, tiene la posibilidad de entender el funcionamiento del poder y de "vivir en las entrañas del monstruo" como diría Martí en referencia a los Estados Unidos, para comprender desde adentro los juegos políticos de su tiempo.

Pero, muy impresionado por la muerte de su gran amigo y colega, el médico, historiador y místico granadino, Lisanuddín Ibn al-Jatib (1333-1375), estrangulado en la cárcel de Fez (Emilio de Santiago, 1986), se refugia durante cuatro

Sorbona como el libro de texto de base para la medicina en Europa.

10 Se escribe Bedjaia en francés, la exBougie colonial. 
años (1375-1379) en el sudoeste de Argelia. Tiempo en el que logra terminar la primera redacción de su Muqaddimah.

Su obra lo lleva a una reclusión de más de cuatro años para posteriormente, regresar a la corte de Túnez para enseñar sus conocimientos. Durante esta estancia busca acabar la primera redacción de la llamada Historia universal (en árabe Kitab al- 'ibar, "Libro de los bereberes"). Su pensamiento, aplaudido por los estudiantes, provoca la reacción de los conservadores juristas que lo presionan para expulsarlo definitivamente de la corte tunecina. El periodo de decadencia islámica no es propicio para las ideas nuevas y revolucionarias del filósofo magrebino que se adelantó a su tiempo.

Ibn Jaldún se instala en El Cairo, enseña Derecho en la Universidad de Al Azhar ${ }^{11}$ y recibe el cargo de Gran Qadi (juez principal). Su docencia será turbulenta porque perderá y reencontrará su cátedra varias veces, pero durante sus 14 años en El Cairo podrá revisar su obra y agregarle hacia 1395, un apéndice, El Ta'rif, una verdadera síntesis de su obra, además de un trabajo autobiográfico.

En 1400, Tamerlán, el mongol, lo lleva a su corte instalada en Damasco ${ }^{12}$, en dónde Ibn Jaldún deja de producir intelectualmente y terminará su vida en $1406^{13}$. Su encuentro con el gran conquistador mongol es descrito por el propio autor en su autobiografía. El magrebí acompañó al sultán Abú Al Saadat Farag Ibn Barquq a Siria para enfrentarse a las tropas asiáticas, pero el regreso del monarca mameluco a El Cairo, después de una herida, deja a los científicos que lo acompañaban, como Ibn Jaldún, solos en Damasco. Debido a esto, el pensador magrebino decide reunirse con el liderazgo mongol para evitar la destrucción de la ciudad como pasó en Bagdad 150 años antes.

Según Ibn Jaldún, durante su encuentro con Tamerlán, el líder mongol, después de preguntarle sobre Marruecos y otras partes del mundo islámico, quedó tan cautivado por el amplio conocimiento del magrebí (Al Tawansy, 1967), que lo sumó a su corte como consejero.

11 La universidad de Al Azhar, fundada en el 969, es la segunda universidad (después de la de los Qarawiyin de Fez, fundada en 859) más antigua del mundo que sigue funcionando hasta la actualidad

12 Tamerlán, en su proceso de conquista del Medio Oriente se instala en Damasco, donde recibe a Ibn Jaldún.

13 Muchos autores, en particular los que están en Internet como el Dr. A. Zahoor, señalan la muerte de Ibn Jaldún en el año 1395, lo que es obviamente un error porque en este año, Tamerlán aún no había invadido el Medio Oriente y es un hecho histórico que Ibn Jaldún se reunió con el gran conquistador mongol. 
Además de sus aportes como historiador, Ibn Jaldún propuso una "ciencia de la sociedad" como el mismo la denominó, que en el siglo XIX Agusto Comte bautizó como sociología.

\section{De la historia a la sociología}

Al parafrasear a Nassif Nasser (1982), podemos hablar de un pensamiento realista de Ibn Jaldún. Este es uno de los primeros teóricos de la historia de las civilizaciones. De él, Arnold Toynbee dijo que "concibió y formuló una filosofía de la Historia que es sin duda el más grande estudio que jamás fue creado por ningún espíritu en ningún tiempo ni en ningún país" (Toynbee, 1935, p. 72).

Sin embargo, los trabajos sobre Ibn Jaldún, en el siglo XIX conllevaron a hacer de él (en la filosofía europeísta) un pensador solitario, sin ninguna influencia en los demás intelectuales. Fue relegado, a pesar de su innegable peso en el pensamiento tanto islámico como occidental (Ernest Geller, 1986), como un pensador marginal, sobre todo durante la fase colonial que buscaba reducir los aportes islámicos en la cultura occidental. En el siglo XX, gracias a los aportes de la escuela francesa de sociología, en particular Yves Lacoste, se ha tratado de compararlo con pensadores como Maquiavelo, Montesquieu, Hegel, Comte, y en la década de los sesenta del siglo XX con Marx por su acercamiento materialista de la historia y con Aron, por su sociología histórica.

En su Muqadimah, su interés principal es la identificación de los factores psicológicos, económicos, sociales, políticos y del medio ambiente que afectan a los hechos históricos y a la historia misma (Rabi, 1967, p. 23) ${ }^{14}$. Además se enfoca en los factores que explican el auge y la decadencia de las civilizaciones y en este sentido es también un precursor de Paul Kennedy (1991) y de los pensadores de la historia como un fenómeno cíclico. Con estos planteamientos podemos decir que fundó una ciencia del desarrollo social (Alatas, 2014, p. 43) o Ilm al Iytimaa (la ciencia de la Sociedad o la Sociología) como él mismo la denominó. Raymond Aron, aún y sin citarlo plantea de manera muy similar estas premisas que ya más de siete siglos atrás hiciera Ibn Jaldún al mencionar que todo análisis de la realidad social debe ser filosófico, teórico, histórico, sociológico y praxeológico.

Su trabajo político y administrativo con todos los reinos en África del Norte y en la España musulmana de su época le permitió entender el funcionamiento

14 En particular "the Method of Ibn Khaldoun, New Science of Human association" y el capítulo 3 (pp. 48-72) sobre "the concept of Assabiya". 
del modo de producción magrebino, que no respondía a la lógica de los modelos egipcio o meso-oriental, más cercanos a lo que Marx llamó el modo de producción asiático o despótico. En efecto, en el Magreb, el poder del soberano no descansaba sobre un ejército permanente y una burocracia real, sino sobre un complejo sistema de alianzas con las tribus no sometidas, pero que otorgaban su apoyo a cambio de beneficios monetarios o de tierras. Este peculiar sistema de poder provocaba una gran inestabilidad política por los cambios permanentes de alianzas y no permitía la realización de grandes obras hidráulicas como en los modelos despóticos clásicos. Podríamos inclusive subrayar que el caso norafricano es una excepción a la generalización marxista de los modos de producción, pero muy difundida si analizamos los casos africanos o de Asia central que Marx no logró aprehender. De hecho, este sistema analizado por Ibn Jaldún hace más de siete siglos sigue funcionando en la actualidad. En la Libia de Gadafi, el sistema político del dictador descansaba sobre su alianza con los jefes tribales y las prebendas que repartía a los líderes locales.

También, Ibn Jaldún sostenía que la economía era el motor de la historia (Aziz al Azmeh, 1982, pp. 9-47), tesis que encontraremos hasta el siglo XIX con Marx y Engels. Los planteamientos jaldunianos para analizar el devenir de las sociedades magrebinas fueron inclusive retomados por el propio Engels.

En un artículo publicado en Die Neue Zeit en el año 1894-1895, Engels escribió:

El islam se acomoda bien a los orientales, especialmente a los árabes, esto es, por un lado, los hombres de las ciudades que practican comercio y la industria y, por el otro, los beduinos nómadas. Pero, hay aquí la semilla de una colisión periódica. Los hombres de la ciudad al hacerse opulentos y ostentosos, se vuelven laxos en la observancia de la 'Ley'. Los beduinos, pobres $\mathrm{y}$, por lo tanto, de costumbres austeras, contemplan con envidia y deseo la riqueza y el placer. Se unen bajo la dirección de un profeta, un Mahdi, para castigar al infiel, para restaurar la ley ceremonial y la verdadera fe y, como recompensa, la apropiación de los tesoros de los infieles. Cien años más tarde, naturalmente, se encuentran exactamente en el mismo punto que sus antecesores. Es necesaria una nueva purificación. Surge un nuevo Mahdi. El juego vuelve a comenzar (Geller, 1986, p. 71).

A pesar de algunos errores como confundir el Mahdi, Mesías, con el profeta, o de posiciones subjetivas como hablar de la envidia de los beduinos o que el islam se acomoda a los árabes, el texto anterior hubiera podido ser extraído de la Muqadima de Ibn Jaldún. "Es obvio que Engels, entonces, había tenido acceso a las ideas de Ibn Jaldún. La existencia de una traducción le ahorró la necesidad de aprender un lenguaje semítico, por el cual, como escribió a Marx, sentía 
aversión. De hecho, Marx había anotado a Kovalesky, cuyo capítulo sobre Argelia contenía la traducción de Ibn Jaldún, hecha por Slane, en su bibliografía" (Geller, 1986, pp. 71-72).

Ibn Jaldún dijo que "he escrito un libro sobre historia en el cual analizo las causas y efectos del desarrollo de los Estados y de las civilizaciones, pero he organizado este material del libro de una manera poco convencional, en un camino innovador" (Ibn Jaldún, 1979, p. 8).

\subsection{La sociología de Ibn Jaldún}

En su obra analiza diversos aspectos del pensamiento humano. Al Muqadima

...tiene importancia por ser su obra más completa, es un estudio de historia universal en el cual se manifiesta como filósofo de la historia en la interpretación de algunos acontecimientos y como historiador en su método y en los asuntos que trata. (La obra) abarca todos los aspectos de la historia y de la sociedad. Como historiador (...) se adelantó a mucho en la crítica de la documentación, en el planteamiento de los acontecimientos históricos, así como en la búsqueda de las razones que han provocado cada uno de ellos. La idea 'organicista' de los imperios es uno de sus más valiosos aportes en el campo de la filosofía de la historia. Es oportuno indicar que al respecto Ibn Jaldún se adelantó seis siglos a Splenger. El historiador musulmán aseguró que los imperios, igual que las personas, tenían su propia vida (Roberto Marín, 1985, p. 91).

Ibn Jaldún (1979), presenta en la introducción de su obra Al-Muqadima, a la historia entendida como ciencia, define el objeto de estudio, el hecho histórico, los principios y los métodos de la Historia como disciplina crítica, así como la posibilidad de su entendimiento. El autor enumera los constantes errores y equívocos de los historiadores y enfatiza la importancia de la crítica. En este sentido, el autor distingue tres niveles de análisis:

- $\quad$ El nivel histórico: los acontecimientos o los hechos históricos.

- $\quad$ El nivel historiográfico: cómo analizar estos hechos históricos.

- $\quad$ El nivel de la filosofía de la historia: darle un sentido a la historia, no como dinástica o de hechos aislados, sino como una finalidad y regida por leyes, con causas y efectos. Es una historia cíclica. 
Aunque muchos autores reconocen en la obra de Ibn Jaldún un tratado sobre la filosofía de la historia, Pomian (2006), lo descalifica porque el término nació solamente con Voltaire hasta 1765 y ve en la obra del magrebino una "teología de la historia". Si bien es cierto que Ibn Jaldún fue profundamente religioso (Al Azmeh, 2005) $)^{15}$, sobre todo al final de su vida, en su análisis de las causas de los fenómenos históricos no busca a un creador universal, sino al hombre como actor de su propio devenir. En realidad, la existencia de una parte 'religiosa' en la obra del magrebino se debe más a su voluntad de compromiso con la ortodoxia de su época que a una visión teológica de la historia.

En efecto, si podemos descubrir en la Muqadima una constante referencia al dios del Corán, la búsqueda de las soluciones las más conciliatorias a las cuestiones espinosas de la doctrina, la ambigüedad y, a veces, la oscuridad de sus aseveraciones, todo puede ponerse a cuenta de una prudencia autoimpuesta por la novedad y el carácter perturbador de su pensamiento. Este juicio tiene tal vez algo de verdad, pero solamente hasta un cierto punto. En realidad, un examen atenido de la obra permite ver dos tendencias que a menudo se oponen, pero que son básicamente al servicio una de la otra: la primera se presenta bajo un aspecto innovador y hasta revolucionario, y no duda en cuestionar muchas de las ideas recibidas en materia social, política, cultural y religiosa. Auténticamente racionalista, es ella que hoy día nos extraña y nos fascina. La otra, menos visible, es profundamente conservadora, toda ella orientada hacia la defensa del orden (Cheddadi, 2006, p. 192).

Ibn Jaldún enfatiza la existencia de leyes que explican el devenir histórico y en particular el rol del medio ambiente en la vida de las personas y los fenómenos económicos, planteamiento que será retomado hasta el siglo XIX en Europa para entender los procesos históricos. El autor "asegura que la disposición a las artes y a la civilización, así como al progreso y al bienestar, están condicionadas por los recursos naturales y por el clima de las regiones que el hombre habita. Concede gran importancia a estos asuntos ya que considera que existe una estrecha relación entre el comportamiento social y los fundamentos que lo sustentan" (Guzmán Marín, 1985, p. 100).

Esta visión de la historia, a pesar de sus limitaciones, coloca al pensador islámico como el precursor de la historiografía moderna como el mismo lo señala: "Más la ciencia histórica tiene sus caracteres intrínsecos: que son el examen y la verificación de los hechos, la investigación atenta de las causas que los han producido, el conocimiento profundo de la naturaleza de los acontecimientos y sus causas originales. La historia, por tanto, forma una rama importante de

15 Al Azmeh se enfoca sobre todo en la vertiente mística del historiador. Sin embargo, a pesar de su misticismo, este no interfiere en su pensamiento científico. 
la filosofía y merece ser contada en el número de sus ciencias" (Idem.: 98-99). Ibn Jaldún no podría estar más presente en el pensamiento de Aron cuando este escribe que "la proporción de recursos y el número ha marcado, a través de los siglos históricos, el destino de las naciones y la prosperidad de los pueblos" (Aron, 1985, p. 455).

Su obra además contempla seis interesantes dimensiones para el análisis:

1. Umran o sociología general de la civilización: Ibn Jaldún define al umran y a la asabiya (los lazos intertribales), al desarrollar una teoría de la sociabilidad natural y los condicionamientos del medio físico (lo que lo hace un precursor de la geopolítica) y sus repercusiones culturales y sobre el ser humano.

2. Badiya: o sociología de la beduinidad (referencia a la vida opuesta a la citadina). Ibn Jaldún opone la badiya a la vida citadina, al hacer un estudio de psicología comparada entre dos modos de vida y del paso del uno al otro en el transcurso del proceso histórico.

3. Mulk o tratado de filosofía política. En este apartado se analiza el poder y su ejercicio, la autoridad espiritual del soberano (o califa), el ascenso y la caída de las dinastías y la forma de las instituciones.

4. Hadara: sociología de la citadinidad o de la urbanidad: analiza el fenómeno urbano, la organización de la polis (o ciudad política), hace una tipología del citadino o del hadari (opuesto al badawi de la badiya quien conserva su asabiya).

5. Economía política: Ibn Jaldún analiza las clases sociales, el trabajo en la polis, la economía urbana.

6. Sociología del conocimiento: en esta sección elabora una clasificación de las ciencias (religiosas, racionales, lingüísticas), del lenguaje y su adquisición, de las disciplinas filosóficas y literarias. Ibn Jaldún enfatiza que el uso de la fuerza es un enemigo de la enseñanza y que conduce a la mentira y a la hipocresía. Precisa que:

...el uso de un excesivo rigor en la enseñanza es muy nocivo para los educandos, sobre todo si están todavía en la infancia, porque eso produce en su espíritu una mala disposición, pues los niños que se han educado con severidad... se hallan tan abatidos que su alma se contrae y pierde su elasticidad. 
Tal circunstancia los dispone a la pereza, los induce a mentir y a valerse de la hipocresía, con el fin de evitar un castigo. De este modo aprenden la simulación y el engaño, vicios que se vuelven en ellos habituales y como una segunda naturaleza... He aquí el por qué los pueblos sometidos a un régimen opresivo caen en la degradación (Ibn Jaldún, 1979, p. 1003).

Con estos planteamientos, Ibn Jaldún se vuelve un defensor de la democracia y de la libertad de pensamiento, mucho antes de su surgimiento en Europa. En la situación social del mundo islámico de su época, las condiciones no estaban dadas para poder poner en práctica las lecciones sobre educación del pensador.

Su concepto de umran (umran badaui y umran hadari) abarca toda la estructura social.

La vida salvaje, el relajamiento de las costumbres...los diversos sentimientos de superioridad que unos pueblos tienen sobre otros...las ocupaciones habituales a las que los hombres consagran sus trabajos y esfuerzos... La religión, la ciudad, el domicilio, el poderío, la decadencia y el crecimiento de la población, su disminución, las ciencias y las artes (...) En fin, todo aquello que puede influir en el carácter de la sociedad (Ibn Jaldún, 1979, p. 1020).

El término umran designa en la obra de Ibn Jaldún el conjunto de los fenómenos humanos, es decir los problemas demográficos y económicos, así como que las actividades sociales, políticas y culturales.

Una tribu no puede conquistar y conservar un imperio, a menos que posea ciertas características sociales y políticas que el filósofo designa con el término de asabiya. Ahora bien, esta asabiya, esta fuerza que permite a una tribu crear un Estado, no puede existir más que dentro del marco de umran badaui. Pero la conquista del poder, que provoca el advenimiento de un soberano y que determina la aparición del umran hadari, gracias a los recursos obtenidos entre las poblaciones dominadas, provoca la desaparición de esta asabiya y, por esta misma razón, el ineludible debilitamiento del Estado (Lacoste, 1971, p. 146).

\subsection{El historiador}

"La ciencia que nos ocupa no tiene ninguna ventaja, salvo para las investigaciones históricas" (Ibn Jaldún, 1979, p. 58). Ibn Jaldún abandona la concepción de la utilidad, más o menos inmediata, de la historia -tanto en el terreno moral como en el político-, concepción que está ligada a la función histórica desde 
sus comienzos hasta el siglo XVIII. Se muestra como uno de los primeros historiadores que haya estudiado la historia como un fin en sí, y que haya concebido claramente la originalidad de esta disciplina tanto en lo relacionado con su objetivo como en sus métodos.

En su advertencia a los historiadores, Ibn Jaldún plantea que para lograr un trabajo científico:

...Es necesaria seguir la regla para distinguir entre lo verdadero y lo falso en la Historia está basada en su posibilidad o su imposibilidad. Así, debemos examinar la sociedad humana y separar las características que son esenciales e inherentes a su naturaleza de los que son accidentales y que no deben ser tomados en cuenta (...). Si hacemos esto, tenemos una regla para separar la verdad histórica del error por medio de métodos demostrativos que no admiten ninguna duda. Es una piedra angular para los historiadores de verificar lo que están relatando (Lacoste, 1971, p. 9).

Ibn Jaldún analiza la dinámica de las relaciones tribales y los sentimientos intergrupales que denomina Al-Asabiya (Rabi, 1967, pp. 42-72). La existencia de esta asabiya (fuerza de unión, de cohesión sanguínea, de identidad de interés y de comportamiento que es la piedra fundacional de un grupo) permite entender por qué un grupo étnico o tribal puede llegar al poder o perderlo. La civilización humana es una repetición rítmica de este hecho ${ }^{16}$, pero en el caso del Norte de África, estos cambios se dan cada 120 años (tres generaciones). Es a partir de la experiencia del Magreb (que conoce desde adentro), que Ibn Jaldún busca entender la lógica árabe-musulmana.

La primera generación tiene la solidaridad tribal que es un sentimiento de los beduinos o de la gente del campo, por lo cual el grupo busca subir al poder para imponer su soberanía. En este momento entra en juego un factor civilizatorio, la religión, que es un elemento de la superestructura dependiente de los determinantes geográficos, sociohistóricos. La religión es parte de esta asabiya. La segunda generación es la administradora del imperio y por ende de hacer respetar la ley religiosa, en su encuadre urbano y administrativo. La tercera es la que disfruta de las riquezas acumuladas por lo cual abandona la práctica rigurosa de la religión y pierde la asabiya por convertirse en una elite urbana y mundana. El abandono de la cohesión social permite que otra tribu que la tiene pueda tomar el poder y de nuevo el ciclo se repite.

16 Este análisis de Ibn Jaldún va a ser retomado por diversos autores a lo largo de la historia. El último sería Paul Kennedy (1991) con su Auge y decadencia de las grandes potencias. 
Así a cada fase del proceso histórico, corresponde un tipo de comportamiento espiritual. La religión tiene una función política y administrativa de control de la población y se inscribe dentro de la cohesión social para lograr el mulk. Dentro de esta visión la propaganda religiosa o la difusión del islam constituye el lazo unificador del grupo. En la tercera generación, el abandono de la da'wa conlleva a una caída de la asabiya y por ende, del debilitamiento del poder y su posterior caída. Este ciclo recuerda el péndulo religioso de Hume, el paso de las civilizaciones de una fase rigorista (la primera generación de Ibn Jaldún) a una fase laxa en términos religiosos (la tercera generación).

Para él, la religión es un instrumento del poder y de control de la población. No busca una finalidad divina a la historia ni a la religión. No hay presencia de Dios en el devenir histórico ni la búsqueda de una vida en el más allá. Así, el sentimiento religioso se instrumenta, se desnaturaliza y se disuelve al mismo tiempo que los lazos de interés y de solidaridad existentes entre el grupo. Este planteamiento chocó con el rigorismo religioso predominante en África del Norte. En la medida que la historia son hechos irrepetibles, Ibn Jaldún subraya lo irracional del recurso al modelo del profeta que manejan los líderes políticos para lograr sus fines políticos. No obstante, como elemento de poder es un instrumento racional que permite a los soberanos un control efectivo de él.

El primer elemento fue de orden epistemológico: darle a la historia un lugar en el saber humano. Para entenderla, tiene que definir su objeto de estudio, la realidad vivida por las personas y los procesos sociales y no solamente los procesos de las dinastías reales y buscar una lógica a los procesos universales. Tampoco, se trata de un devenir, una finalidad, como las justificaciones divinas o las leyes del marxismo. En este sentido su reflexión se centra sobre los fenómenos y las leyes de la evolución de la sociedad.

El estudio de la "sociabilidad natural", el umran, es la nueva ciencia que nos permite entender los mecanismos de los fenómenos históricos y de los comportamientos de los seres humanos. Los hechos son singulares e irrepetibles, pero para entenderlos, debemos insertarlos en el conjunto global. A pesar de su singularidad, existe un proceso estructural que los une y que les da una razón. Esta posición metodológica coincide justamente, con la propuesta de Raymond Aron, varios siglos después, al aseverar en su obra Paz y guerra entre las naciones (Raymond Aron, 1985) que si bien los fenómenos son únicos e irrepetibles (la singularidad histórica), éstos se hayan determinados por un elemento recurrente y constante: las regularidades sociológicas, intrínsecas al comportamiento social. 
Este análisis racionalista elimina tanto la naturaleza humana, la psicología de las personas (el papel del individuo) como la religión en el entendimiento de la historia. El ser humano no es responsable individualmente de los cambios, lo que viene a romper con la tradición de los soberanos como los hacedores de ésta. Esta ruptura será retomada solamente seis siglos después de él, cuando en el siglo XX la escuela francesa de los Annales con Renouvin y Duroselle (1991), plantea la existencia de las "fuerzas profundas" que mueven a los procesos universales.

Este proceso de análisis, permite a Ibn Jaldún elevarla a la categoría de Ciencia contrariamente a sus predecesores. En este sentido, es particularmente severo contra ellos (son "ignorantes, parciales, incapaces"). La historia es la ciencia de los hechos y el magrebino es un pionero en su planteamiento del estudio, al partir de cuatro puntos esenciales:

1. Relacionar los hechos entre ellos a través de las causas y los efectos.

2. Hacer analogías entre el pasado y el presente (la historia como laboratorio diría la sociología histórica).

3. Tomar en consideración el medio ambiente (influencia de la geografía sobre los seres humanos, principio de la geopolítica).

4. El papel de la economía en la historia (precursor de los análisis marxistas).

En su Introducción, Ibn Jaldún presenta su propuesta de análisis de la historia, y enfatiza la credibilidad de los científicos y el rigor para la determinación de la verdad científica. Sin embargo, él mismo fue criticado por no haber utilizado su lógica en su obra monumental de la Historia Universal (retoma los elementos tradicionales de la interpretación histórica a pesar de su énfasis en una nueva metodología interpretativa). Esta es la misma crítica que se le ha hecho a Carlos Marx que plantea el uso de la dialéctica histórica, cuando su obra El Capital carece de este instrumento analítico y retoma la lógica tradicional como lo demostró José María Calderón (1978) en su anti-método.

En un estudio comparativo entre Ibn Jaldún y Robert Putnam (autor de Making Democracy), Maverick F. Fisher (1995) hace énfasis en las naturalezas opuestas de los objetos de estudio (la Italia cristiana del siglo XX para Fisher y el Magreb musulmán del siglo XIV para Ibn Jaldún). Sin embargo, hay varias similitudes entre los dos pensadores. Los dos autores parten de la misma problemática; en particular, por qué medios y en qué condiciones los grupos humanos logran arreglarse por sí mismos en unidades que funcionan relativamente y que son cohesionadas. Tanto Ibn Jaldún como Putnam 
reconocen que la sociedad civil tiene mucho que ver con la cooperación entre los ciudadanos individuales. Putnam mide la salud de una sociedad civil en el número de organizaciones privadas. El grado de asociacionismo de los ciudadanos, que sea en los clubes de boliches o de alces, es un indicador de cómo es la sociedad civil. Ibn Jaldún ve la sociabilidad de la sociedad (umran) con los mismos estándares, a partir del sentimiento grupal o asabiya. Este sentimiento de la solidaridad del grupo permite que los ciudadanos se unan para el bien funcionamiento de toda la sociedad civil (Fisher, 1995, p. 85).

Para ilustrar esta cohesión social, Ibn Jaldún toma el ejemplo de la batalla de Qadisiyah que puso fin al imperio Sasánida en el 636 d. C., y la batalla de Yarmuk que expulsó a las tropas bizantinas del Medio Oriente, cuatro años después de la muerte del Profeta del Islam. Esta victoria abrió las puertas de Asia a las tropas islámicas y puso fin al Imperio persa o más bien islamizándolo. Para Ibn Jaldún:

...el islam es probablemente la más poderosa fuerza unificadora en la sociedad de nuestros días (de la época del autor). Apenas unos siglos antes, fue el poder de cohesión de la religión del Profeta Mahoma que permitió a las hordas del desierto dominar toda la Península arábiga y conquistar una gran parte del mundo (Ibn Jaldún, 1979, p. 355).

Como lo describe Ibn Jaldún, "los ejércitos de los musulmanes en Al-Qadisiya y en Yarmuk totalizaban 30,000 hombres en cada caso mientras que las tropas persas en Al-Qadisiya eran de 120,000 y las tropas de Heraclius llegaban a 400,000. Ninguna de las dos partes era capaz de derrotar a los musulmanes" (Ibn Jaldún, 1979, p. 126).

Así, el aporte de Ibn Jaldún no se limita solamente a la historia como fue reconocido por su obra Al-Muqadima, sino que trasciende las fronteras de la ciencia histórica para abarcar la filosofía, la psicología, la sociología (Alatas, 2014) $)^{17}$ y la Ciencia Política ${ }^{18}$, además de la educación, la economía ${ }^{19}$, así como la geopolítica para mencionar solamente algunas disciplinas. Con su planteamiento de que es el clima que influye sobre el comportamiento de los habitantes, en sus costumbres y en su desarrollo intelectual, el magrebino

17 Syed Farid Alatas en una obra reciente que rescata el pensamiento sociológico de Ibn Jaldoun y trata de ver las posibles aplicaciones para entender al Mundo Árabe de hoy.

18 En su libro clásico de 1967, Muhammad Mahmoud Rabi elabora una teoría política jalduniana a partir de su obra magna de la Muqadima.

19 Mohammad Aly Nashat, en una antigua obra publicada por el gobierno realista egipcio en 1945, ya había planteado los principios de economía política que se encuentran en la obra de Ibn Jaldún, en particular, su teoría de los impuestos y lo ve como un pionero de la economía. 
se adelantó a los planteamientos de la geopolítica decimonónica y del carácter vivo del Estado que encontramos en las obras de la geopolítica clásica.

La reflexión de Ibn Jaldún (...) resulta excepcional por cuanto recibe y asimila toda la anterior reflexión islámica fragmentada en jurisprudencia, teología, ética, filosofía e historia, y, trascendiéndolo todo, crea la sociología política, incluso una sociología histórica, indagando la esencia de la vida del ser humano en sociedad, y llegando a concluir que el Estado es una institución natural, en el cual la religión forma ni más ni menos su ideología: "la autoridad -dice- es una institución natural de la humanidad", con lo cual va más allá de las propuestas naturalistas de los filósofos, y desde luego deja muy atrás a las interpretaciones del origen divino del Estado propias de otros grupos de pensadores (Viguera, 1990, p. 362).

Con este planteamiento, Ibn Jaldún rechaza la naturaleza divina tanto del Estado como del poder e incluye a la religión en lo que muchos siglos después, Marx llamaría la superestructura o "un aparato ideológico del Estado" dentro del marxismo francés del siglo siguiente. Para el autor magrebino, un Estado puede existir solamente si se reúnen tres elementos esenciales: una base para la fuerza (el monopolio legítimo de la violencia), una capacidad de organización (la estructura política estatal y la burocracia) y una ideología aglutinante (los aparatos ideológicos de Estado). Un texto del siglo XIV, pero con resonancias modernas.

\section{Conclusiones}

Los múltiples aportes de Ibn Jaldún lo colocan como historiador, precursor de la economía liberal (por su teoría de los impuestos), como realista y como sociólogo. Lo que equivale a decir que queda un gran trabajo a realizar para que Ibn Jaldún sea citado por la historia para interpretar e incluso juzgar la del Magreb y del islam. Con mucha razón los autores serios e investigadores lo consideran «el padre de la sociología», «el fundador de la economía política» y «un hombre sin época» y aunque pocos lo identifican en la teoría internacional, es innegable su presencia a través de los análisis que realizó de las relaciones de poder, los procesos de dominación, auge y caída de los imperios, desde una perspectiva, que hoy llamamos sociología histórica, propuesta por Raymond Aron en la segunda mitad del siglo XX.

Su análisis de los procesos históricos en el Magreb de su tiempo, con un enfoque histórico, pero basado en el estudio de las fuerzas profundas de los cambios, permite considerarlo como un precursor de la sociología histórica que en 
el siglo XX Raymond Aron bautizó como la teoría de la Sociología Histórico. Nassif (1982), ya había definido a Ibn Jaldún dentro de la corriente realista, pero para nosotros, si bien es cierto que lo podemos denominar realista, su metodología de análisis lo vincula directamente con la Sociología Histórica.

\section{Referencias bibliográficas}

Tawansy, A., Abul Fotouh, M. (1967). Ibn Khaldoun. El Cairo, Egipto: Edit. The Supreme Council for Islamic Affairs, Studies in Islam Series, N. 5.

Azmeh, A. (2005). Ibn Khaldoun: An essay of Reinterpretation. Nueva York, Estados Unidos: Frank Cass and Company Limited.

Alatas, S. F. (2014). Applying Ibn Khladoun: The Recovery of a lost Tradition in Sociology. Londres, Gran Bretaña: Routledge.

Arenal, C. (1987). Introducción a las relaciones internacionales. Madrid, España: Tecnos.

Aron, R. (1985). Paz y guerra entre las naciones. Madrid, España: Alianza Universidad.

Azmeh, A. A. (1982). Ibn Khaldoun An essay in Reinterpretation. Nueva York, Estados Unidos: Frank Cass Company Limited.

Calderón, J. M. (1978). El anti-método. Ciudad de México, México: Fondo de Cultura Económica.

Chaix-Ruy, J. (1954). Sociología y psicología de la vida social en la obra de Ibn Jaldun. Revista Mexicana de Sociología 4 (octubre-diciembre): 7-22.

Cheddadi, A. (2006). Ibn Khaldûn. L'homme et le théoricien de la civilisation. París, Francia: Editions Gallimard, Col. Bibliothèque des Histoires.

Elía, S. (s/f). La civilización del islam. Pequeña enciclopedia de la cultura, las artes, las ciencias, el pensamiento y la fe de los pueblos musulmanes. Buenos Aires, Argentina: Instituto Argentino de Cultura Islámica.

Engels, F. en Die Neue Zeit, citado en Geller, E. (1986). La sociedad musulmana. Ciudad de México, México: FCE.

Fisher, M. F. (1995). Ibn Khaldoun's Civil Society. Midterm paper comparing the views of Ibn Khaldoun and the American political scientist Robert Putnam for a class studying civil society at UT. Recuperado de http://www.la.utexas. edu/users/chenry/civil/archives95/csspapers/0017.html

Geller, E. (1986). La sociedad musulmana. Ciudad de México, México: FCE. 
Guarch, G. H. (2008). Ibn Jaldún, la memoria de la historia. Almeria, España: Arráez editores, S. L.

Gutiérrez, G. (1997). Teoría de las Relaciones Internacionales. Ciudad de México, México: Harla.

Hitti, P. K. Récits de l'Histoire des Arabes Lacoste, citado en Lacoste, Y. (1971). El nacimiento del Tercer Mundo: Ibn Jaldún. Barcelona, España: Ediciones Península, col. Historia, Ciencia, Sociedad, núm. 73.

Ibn Jaldún (1979). El Muqadima. Tarij el alama (La Muqadima. Historia universal). Beirut, Líbano: Dar el Kitab El lubnani.

Ibn Jaldún (1997). Introducción a la historia universal (Al-Muqaddumah). Ciudad de México, México: FCE.

Kennedy, P. (1991). Auge y decadencia de las grandes potencias. Ciudad de México, México: Edit. Diana.

Lacoste, Y. (1984). Ibn Khaldoun: The birth of History and the Past of the Third World. Londres, Gran Bretaña: Verso.

Lacoste, Y. (1971). El nacimiento del Tercer Mundo: Ibn Jaldún. Barcelona, España: Ediciones Península, col. Historia, Ciencia, Sociedad, núm. 73.

Marín, R. (1985). Ibn Khaldoun (1332-1406) y el método científico de la historia. Revista Estudios (6), Universidad de Costa Rica.

Martínez-Gros, G. (2006). Ibn Khaldoun et les sept vies de l'Islam. París, Francia: Edit. Sindbab, Col. Actes Sud.

Nashat, M. A. (1945). Ibn Khaldoun, Pioneer Economist. El Cairo, Egipto: Government Press.

Nassif, N. (1982). El pensamiento realista de Ibn Jaldún. Ciudad de México, México: FCE.

Pomian, K. (2006). Ibn Khaldûn au prisme de l'Occident. París, Francia: Editions Gallimard, Bibliothèque des Histoires.

Rabi, M. M. (1967). The political Theory of Ibn Khaldoun. Leiden, Países Bajos: E. J. Brill.

Renouvin, P. y Duroselle, J. B. (1968). Introducción a la política internacional. Madrid, España: Rialp Ediciones.

Renouvin, P. y Duroselle, J. B. (1991). Introduction à l'histoire des Relations Internationales. París, Francia: Armand Colin.

Santiago, E. (1986). El polígrafo granadino, Ibn al-Jatib y el sufismo. Granada, España: Diputación Provincial de Historia del Islam. 
Toynbee, A. (1935). A Study of History, tomo 3. Londres, Gran Bretaña: Oxford University Press.

Viguera, M. J. (1990). El mundo islámico. Historia de la teoría política, compilado por Fernando Vallespín. Madrid, España: Alianza Editorial.

Zeraoui, Z. (2013). El pensamiento filosófico en el Islam clásico. Ciudad de México, México: Trillas. 